\title{
A Non-Oxidative Approach Towards Hybrid Silicon Nanowire- Based Solar Cell Heterojunctions
}

\begin{abstract}
A general method for the non-oxidative termination of silicon nanowires (Si NWs) is reviewed. Oxide-free Si NW have been successfully alkylated in the lab using a two-step chlorination/alkylation process. The distinctive properties of the resulting Si NW have been taken advantage of by integrating the Si NWs into functional devices such as solar cells. Moreover, molecularly terminated Si NWs exhibit lower defect density emissions than unmodified Si NWs. This, in part, explains the better performance of the molecularly terminated Si NW-based solar cells. Solar cells that use organic-inorganic hybrid $\mathrm{Si}$ NWs as absorbers show an increased open-circuit voltage $\left(V_{o c}\right)$, an increased short-circuit current $\left(J_{s d}\right)$ and a higher fill factor (FF). The aim of chemical functionalization is to protect Si NWs from extensive oxidation, add functionality and to adjust surface electronic properties such as the work function, surface Fermi level and band bending. The stability of the terminated of Si NWs was found to be dependent on the molecular chain length, molecular coverage, interaction type (п-п or $\sigma-\sigma)$, surface energy and Si NW diameter.
\end{abstract}

Keywords

Silicon Nanowire - Oxide Free Silicon - Two-Step Process Chlorination/Alkylation Process $\bullet$ Hybrid Solar Cell $\bullet$ Oxidation Resistance $\bullet$ Photoemission $\bullet$ Heterojunction

(c) Versita Sp. z o.o.

\begin{tabular}{|c|c|}
\hline $\begin{array}{l}\text { Muhammad Y. Bashouti }{ }^{\star *} \text {, } \\
\text { Jürgen Ristein }{ }^{2} \text {, }\end{array}$ & $\begin{array}{l}\text { Hossam Haick } \\
\text { Silke Christiansen }\end{array}$ \\
\hline $\begin{array}{l}{ }^{1} \text { Max-Planck-Institute for the Science } \\
\text { of Light, Günther-Scharowsky-Str. 1, } \\
\text { D-91058 Erlangen }\end{array}$ & $\begin{array}{l}{ }^{3} \text { The Department of Chemical Engineering } \\
\text { and Russell Berrie Nanotechnology } \\
\text { Institute, Technion - Israel Institute of } \\
\text { Technology, Haifa } 32000 \text {, Israel }\end{array}$ \\
\hline $\begin{array}{l}{ }^{2} \text { Technical Physics, University of } \\
\text { Erlangen - Nürnberg, 91058, } \\
\text { Erlangen, Germany }\end{array}$ & $\begin{array}{l}{ }^{4} \text { Institute of Nanoarchitectures for Solar } \\
\text { Energy Conversion, Helmholtz-Center } \\
\text { Berlin (HZB) Hahn-Meitner-Platz 1, } \\
\text { D-14109 Berlin }\end{array}$ \\
\hline
\end{tabular}

Received 17 December 2012 Accepted 13 April 2013

\section{Introduction}

In recent years, a wide variety of one-dimensional nanostructures requiring many different synthesis, modification and characterization methods, have been extensively studied [1,2]. Nanowires are considered to be an important category of onedimensional nanostructures with promising characteristics for applications in electronics [3], optoelectronics [4], photovoltaics [2,5-15] and sensing [16-18].

Silicon nanowires ( $\mathrm{Si} \mathrm{NWs}$ ) have received the attention of many scientists in the last decade as a means to decrease electronic device size while preserving the overall industrial facility production process, thus reducing process redesign costs [19-21]. Si NWs have been characterized through a wide variety of methods such as electron microscopy, x-ray photoelectron spectroscopy (XPS), electron beam induced current (EBIC)/ electron backscattered diffraction (EBSD), photoluminescence (PL) and FT-IR spectroscopy, Raman spectroscopy, etc. Moreover, their successful integration into electronic and photovoltaic devices such as field effect transistors (FETs) $[12,19,22,23]$ and solar cells $[7,11,24-26]$ has revealed their potential to become the mainstream building blocks of future nanodevices.

The fabrication of hybrid Si NWs in combination with organic and inorganic materials via a bottom up route, allowing for fairly accurate control over the NW diameter, length and doping, is currently under research. The large surface area per unit volume of NWs makes them highly sensitive to surface characteristics such as surface morphology, topography and physical/chemical bonds with other atoms and molecules. Indeed, the termination of surface dangling bonds with chemical and/or biochemical moieties is expected to have a significant impact on the final physical and chemical properties of Si NWs. Therefore, the Si NW-based composites can be scaled down to the molecular level by applying surface functionalizations, which cover the Si NW surfaces with molecules bonded to individual surface atoms. The resulting Si NWs are known as "hybrid-Si NWs" [27,28]. The presence of oxide in Si NW surfaces is undesirable for subsequent applications and can have a large detrimental effect on Si NW device performance. When hybrid Si NW devices are exposed to air, oxidizing agents such as water and oxygen form an undesirable layer of oxide with high impurity levels, which can result in uncontrolled oxide/silicon interfaces. Thus, to be effective, Si NWs require a form of protection against oxidation. Surface bonds, which are formed during the functionalization of NWs, can enhance oxidation resistance. For example, etched Si NWs and their surface-bound hydrogen atoms exhibit low surface recombination velocities [29]. However, these surfaces tend to oxidize within a few minutes. Another method to functionalize the Si NW with organic molecule is through Si-C 
bonds, which increase the stability time to a few hundred hours at room temperature $[27,28]$. Therefore, surface molecules can affect the reliability of devices over time in addition to inducing very perfect physical properties. Moreover, many future devices will require their building blocks to be selectively sensitive to the environment. For instance, solar cells require Si NWs of high light absorbance with low surface states, while arrays of Si NW gas sensors should be sensitive to certain species in the gas phase. Organic termination has been successfully carried out on two-dimensional surfaces through a variety of methods [30-32]. However, the technique has not been applied on Si NWs so far since this may result in an incomplete coverage of the organic monolayer (i.e. less than one monolayer of coverage) as well as significant amounts of oxygen on the surface. In this article, we first explain the functionalization method for Si NWs through a two-step chlorination/alkylation process and their application in solar cells. Then devices employing oxide-free hybrid Si NWs are described and promising characteristics compared to the bare Si NWs are then expounded upon.

\section{Experimental Procedure}

Synthesis and Growth of Si NW: Si NWs were prepared by the vapor-liquid-solid (VLS) method using chemical vapor deposition (CVD) with silane protected on $\mathrm{Si}(111)$ substrates, (See Figure 1).

The VLS growth sequence can be summarized in the following steps: (a) Evaporation of growth species and their diffusion and dissolution into liquid droplets, (b) Diffusion and precipitation of saturated species at the liquid - substrate interface, (c) Nucleation and growth of desired material on the interface and (d) Separation of droplets from the substrate by further precipitation and the growth of NWs. To synthesize the Si NWs, substrates were etched in dilute HF to remove the native oxide and subsequently covered with a $2 \mathrm{~nm}$ thick Au film by sputtering and then transferred into the CVD chamber. The substrates were annealed at $580^{\circ} \mathrm{C}$ and a pressure of $5 \times 10^{-7}$ mbar for $10 \mathrm{~min}$. The temperature was then reduced to $520^{\circ} \mathrm{C}$ and a mixture of $5-10 \mathrm{sccm}$ (standard $\mathrm{cm}^{3} \mathrm{~min}^{-1}$ ) argon and 5 sccm silane $\left(\mathrm{SiH}_{4}\right)$ was introduced for $20 \mathrm{~min}$ at a pressure of $0.5-2$ mbar to allow for the nanowire growth. The resulting $\mathrm{Si}$ NWs have a distribution of diameters and lengths which have been measured through Scanning Electron Microscopy (SEM), as depicted in Figure 1.

Termination with a Hydrogen Group: To evaluate the thermal stability of hydrogen atoms bonded to Si NW (H-Si NW) surfaces and determine the dominant oxidation mechanisms, $\mathrm{H}$-Si NWs were annealed at atmospheric conditions at six distinct temperatures: $50^{\circ} \mathrm{C}, 75^{\circ} \mathrm{C}, 150^{\circ} \mathrm{C}, 200^{\circ} \mathrm{C}, 300^{\circ} \mathrm{C}$, and $400^{\circ} \mathrm{C}$, each for five different time-spans: $5,10,20,30$, and 60 $\min$. The annealing and hydrogen-termination processes were gentle in the sense that the processes did not melt the Si NWs or change their diameters. It should be noted that the Si NW were immersed in $5 \% \mathrm{HF}$ for $1 \mathrm{~min}$ and in $\mathrm{NH}_{4} \mathrm{~F}$ for an additional $1 \mathrm{~min}$.
Organic Functionalization via Chlorination/Alkylation: One of the most significant methods employed for Si NWs surface functionalization, among those developed for planar silicon, is the versatile two-step chlorination/alkylation process wherein oxide-free silicon surfaces are first covered by chlorine atoms and later by silicon-alkyl surface bonds. The chlorination/ alkylation process was carried out in a reflux system and the water temperature was kept to $5-10{ }^{\circ} \mathrm{C}$ with a slow flow of $\sim 10 \mathrm{ml} / \mathrm{min}$. The hot-plate temperature was kept at $80^{\circ} \mathrm{C}$. (See Figure 2)

Scanning Electron Microscopy: To observe the geometry of as-grown $\mathrm{Si}$ NWs and to assure that no alteration was caused by $\mathrm{H}$-termination and oxidation, SEM was occasionally performed on samples with a S-4800 Hitachi microscope. The voltage and current used for this purpose were $5.0 \mathrm{kV}$ and $10.0 \mu \mathrm{A}$, respectively. The morphologically sensitive secondary electron (SE) detection mode was employed.

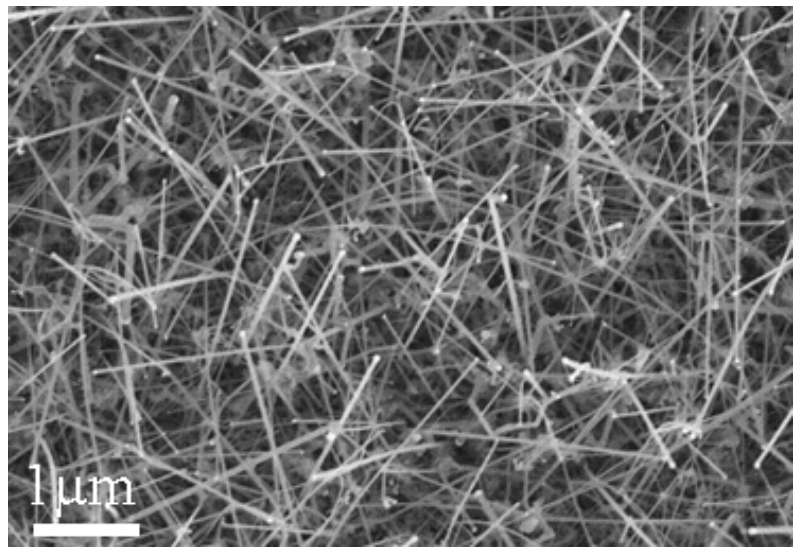

Figure 1. SEM image of VLS-grown Si NWs' with lengths of $3 \pm 1 \mu \mathrm{m}$ and diameters of $60 \pm 10 \mathrm{~nm}$

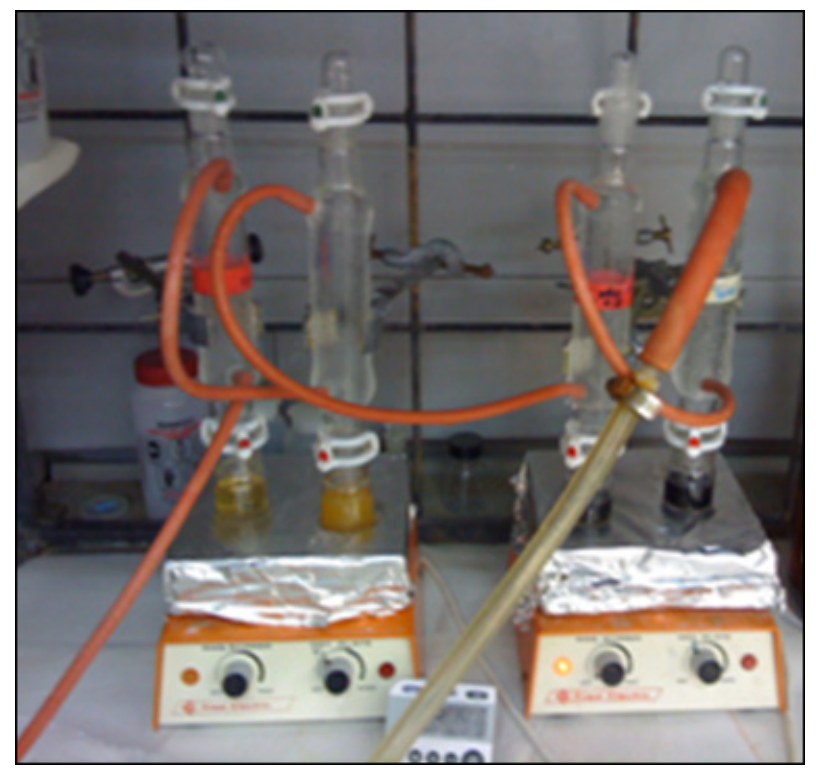

Figure 2. The Chlorination/Alkylation system. In the figure four different reactions are carried out at the same time. 
X-Ray photoelectron Spectroscopy: In this study, X-ray photoelectron spectroscopy (XPS) was extensively utilized to physically and chemically investigate Si NW surfaces. Outputs of XPS measurements are given as spectra in which electron intensities are a function of kinetic energy (or binding energy). Figure 3 depicts a schematic layout of an XPS system including all important components. Core level and valance band photoelectron spectra were excited by monochromatic Al $\mathrm{K}$ radiation $(1,487 \mathrm{eV})$ and collected at a take-off angle of $35^{\circ}$ by a hemispherical analyzer with an adjustable overall resolution between 0.8 and $1.2 \mathrm{eV}$. The surveys were conducted in various electron energy ranges, including the overall binding energy survey ( 0 to $1,000 \mathrm{eV}$ ) and individual spectra for Si $2 p$ (95.0 to $110.0 \mathrm{eV}$ ), C 1s (282.0 to $287.0 \mathrm{eV}$ ) and O 1s (520 to $550 \mathrm{eV})$, which were monitored more accurately in a discrete number of scans. All spectra were taken at room temperature in a UHV chamber of about $10^{-9}-10^{-10}$ Torr pressure. The resulting XPS spectra were analyzed and oxide levels were determined by spectral decomposition using the XPS peak software.

\section{Results and Discussion}

Although the term "hybrid material" is used to describe many diverse systems covering a widespread array of materials, we limit our definition to composite structures with physical or chemical interactions between their organic and inorganic units. In this respect, two classes can be recognized: Class (I) hybrid materials show weak interactions between the two phases, such as van der Waals, hydrogen bonding or weak electrostatic interactions; Class (II) hybrid materials show strong chemical interactions between the components, such as covalent bonding between silicon and organic molecules ( $\mathrm{Si}-\mathrm{C}$ bond). An example of a class // system is illustrated in Figure 4, where alkyl molecules are chemically attached to Si NW via Si-C bonds.

As shown in Figure 1 and 4, VLS grown Si NW with lengths of $3 \pm 1 \mu \mathrm{m}$ and diameters of $60 \pm 10 \mathrm{~nm}$ were obtained. the VLS mechanism is described in Ref. [33]. The fabrication of Si NWs with a controlled diameter, length, and electronic properties is essential to technical applications. The SEM image evidences that $\mathrm{Si}$ NWs were grown in random orientations. The resulting NWs contain thin oxide layers formed during growth. $\mathrm{SiO}_{2}$ thicknesses were $1.6 \pm 0.4 \mathrm{~nm}$. The Si NW grew along the [112] axis showing a single (111) axial twin crossing the entire length.

Organic Functionalization via Chlorination/Alkylation: One of the most significant methods employed for Si NWs surface functionalization, among those developed for planar silicon, is the versatile two-step chlorination/alkylation process wherein oxide-free silicon surfaces are first covered by chlorine atoms and later by silicon-alkyl surface bonds [30,34]. The chlorination/ alkylation process is schematically shown in Figure 5 and can be summarized in the following three steps: (i) termination with hydrogen bonds: Si NW samples are dipped sequentially in buffered HF, (ii) Chlorine termination (Chlorination): H-terminated Si NWs are immersed into a saturated $\mathrm{PCl}_{5}$ solution, (iii) Organic termination (Alkylation): Cl-terminated Si NWs are immersed in alkyl Grignard (R-MgCl).

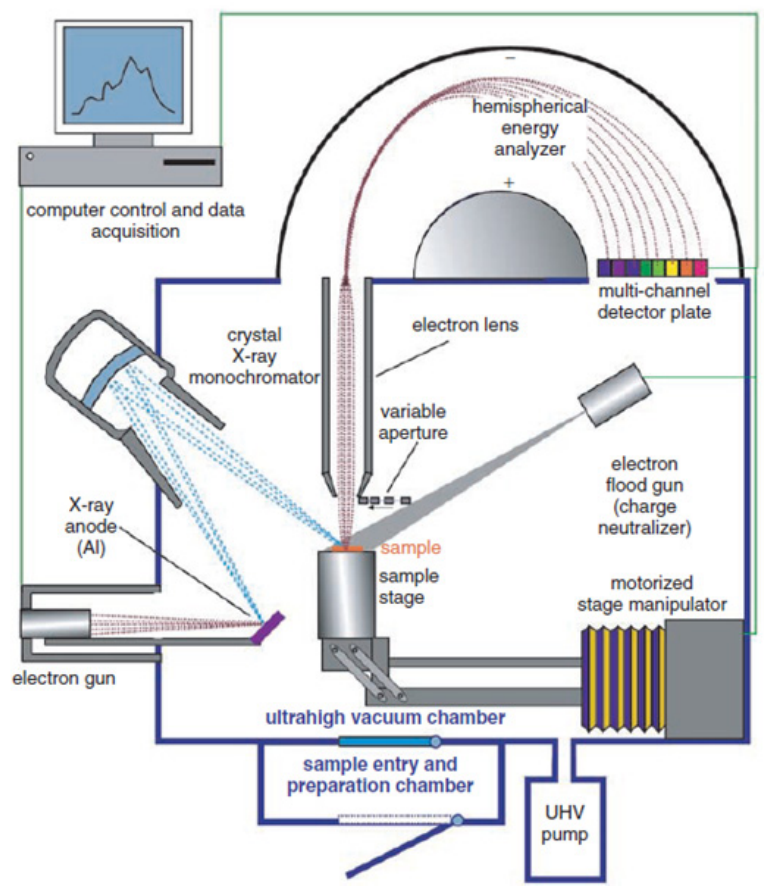

Figure 3. Schematic layout of an X-ray Photoelectron Spectroscopy (XPS) system including the analyzer, sample stage, X-ray anode, $X$-ray monochromator and electron gun.

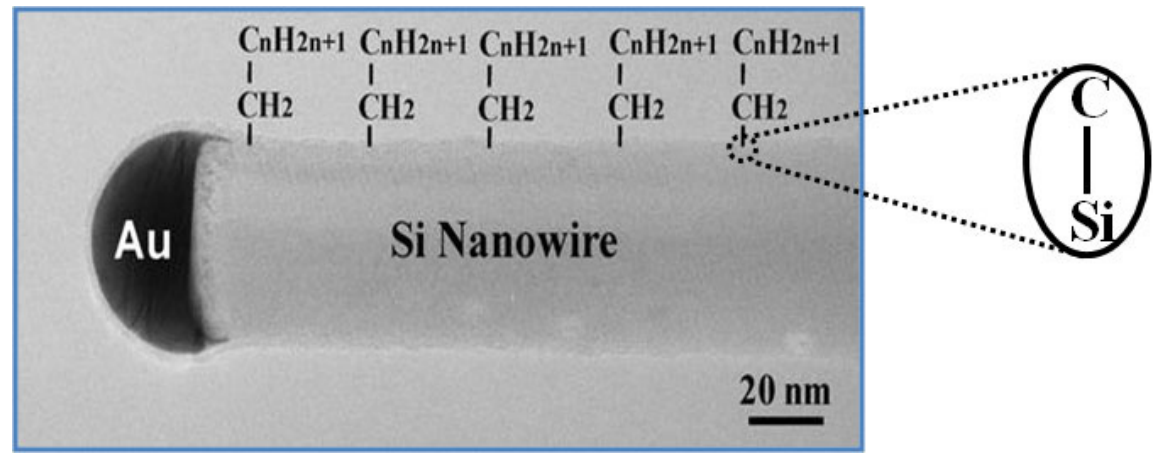

Figure 4. Hybrid Si NW: The organic molecules (alkyl as example) are chemically connected to Si NW by covalent bonds Si-C. Reproduced with permission from ref [27]. 


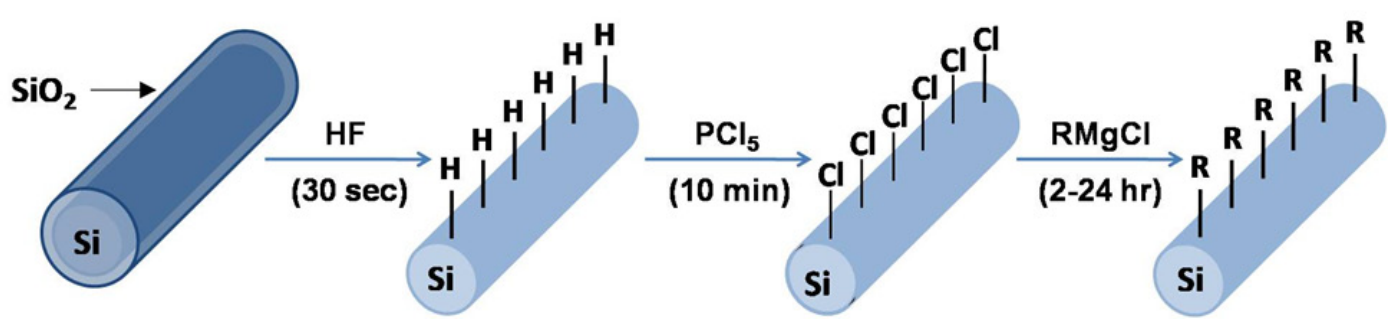

Figure 5. Scheme illustrating the functionalization of Si NWs through the two-step chlorination/alkylation process.

\section{Hydrogen Termination}

In order to understand the stability of the organic molecules on the Si NW surface, we terminate the Si NW with a hydrogen group (i.e. H-Si NW). This has three main advantages (i) it allows us to explore oxidation during very fast stages since hydrogen is only stable for a few minutes (less than $5 \mathrm{~min}$ ), (ii) hydrogen is considered as the smallest group, with a lower diameter than the distance between two adjust $\mathrm{Si}-\mathrm{Si}$ atoms, which as a result, give us full termination i.e. all the Si surface atoms are attached to hydrogen, and (iii) $\mathrm{H}$-terminated is the starting surface for the chlorination/alkylation step. The thermal stability of the hydrogen-terminated Si NWs was investigated by means of the surface sensitive XPS for a variety of temperatures and times. (See experimental section). The oxide growth on Si NWs comprises the formation of interfacial sub-stoichiometric oxides, termed as transient oxides including: $\mathrm{Si}_{2} \mathrm{O}(\mathrm{n}=1), \mathrm{SiO}(\mathrm{n}=2)$ and $\mathrm{Si}_{2} \mathrm{O}_{3}(\mathrm{n}=3)$, followed by the stoichiometric or full oxide $\mathrm{SiO}_{2}$ $(n=4),[35,36]$ as schematically illustrated in Figure 6.

To quantitatively evaluate the oxidation process, Si $2 p$ spectral decomposition was conducted on the spectra. Consequently, the Si $2 p$ spectra includes two silicon spinsplitting peaks as $\mathrm{Si} 2 p_{1 / 2}$ and $\mathrm{Si} 2 p_{3 / 2}$ (in the regime of 99 $100 \mathrm{eV}$ ). (See Figure 7)

The amount of each suboxide present, relative to the amount of intact silicon, can be calculated by dividing the integrated area under the suboxide's peak $\left(A_{\text {siox }}\right)$ by the sum of the integrated area under the Si $2 p_{1 / 2}$ and Si $2 p_{3 / 2}$ peaks $\left(A_{\mathrm{Si} 2} p_{1 / 2}+A_{\mathrm{Si} 2} p_{3 / 2}\right)$. The resulting value is the suboxide intensity, shown by $I_{\text {siox }}$. In addition, the total oxide intensity $\left(I_{\mathrm{ox}}\right)$ can be calculated as the sum of the four suboxide intensities $\left(I_{\mathrm{ox}}=I_{\mathrm{Si} 2 \mathrm{O}}+I_{\mathrm{SiO}}+I_{\mathrm{Si} 2 \mathrm{O} 3}+I_{\mathrm{SiO} 2}\right)$. The total oxide intensity and suboxide intensities and shifts for the Si NWs are illustrated in Figure 8 and compared to hydrogen terminated planar surface (100). Except for $\mathrm{SiO}_{2}$, all the suboxide intensities are comparable with more or less very slight variations over the annealing time. However, Bashouti and co-authors observed different mechanisms at low temperatures (from $25^{\circ} \mathrm{C}$ to $150^{\circ} \mathrm{C}$ ), in which suboxides hold a larger share of the total oxide intensity than at high temperatures $\left(200^{\circ} \mathrm{C}\right.$ to $\left.400^{\circ} \mathrm{C}\right)$ where $\mathrm{SiO}_{2}$ is the main contributor to the overall detected oxide amount [37].

To understand the thermal stability of hydrogen bonds in the two different temperature regimes, logarithm of the oxidation rate as a function of the reciprocal temperatures in the $\mathrm{Si} 2 \mathrm{D}$ and $\mathrm{H}-\mathrm{Si}$ NW specimens during the early stages $(0-10 \mathrm{~min})$ was plotted (Figure 8) [38]. The near-linear behavior allows us to calculate

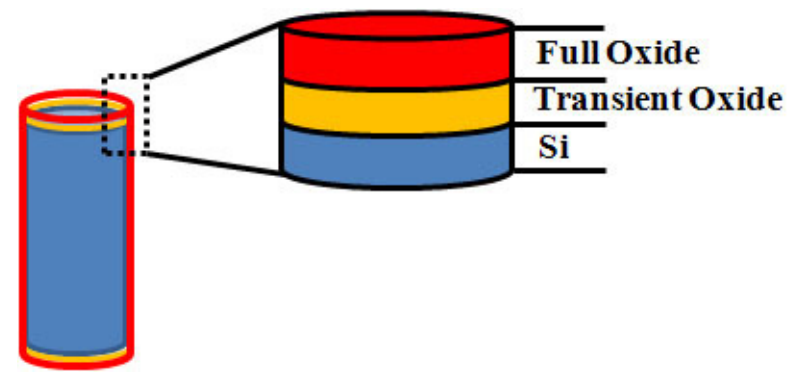

Figure 6. Schematic diagram of SiOx/Si interface.

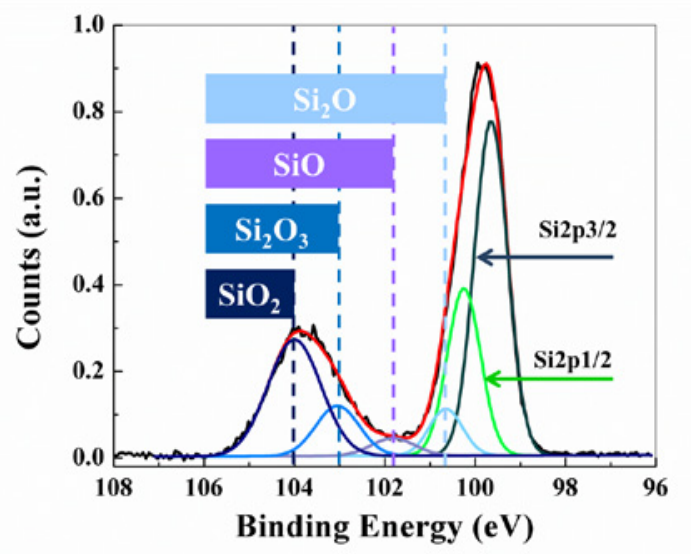

Figure 7. XPS spectrum of Si2p core level emission showing two silicon and four oxide peaks.

the respective activation energies $\left(\mathrm{E}_{\mathrm{A}}{ }^{\mathrm{ox}}\right)$ based on the Arrhenius equation. In the high temperature region, $\mathrm{Si} 2 \mathrm{D}$ and $\mathrm{Si} \mathrm{NWs}$ exhibit similar $E_{A}$ ox of $46.35 \mathrm{meV}$ and $48.22 \mathrm{meV}$, respectively. At low temperatures, $E_{A}{ }^{o x}$ values were estimated as $35.20 \mathrm{meV}$ for $\mathrm{Si}$ 2D and $23.31 \mathrm{meV}$ for Si NWs [39]. The lower $\mathrm{E}_{\mathrm{A}}{ }^{\text {ox }}$ of Si NWs may correspond to the strain induced by dangling bonds rebonding at the (110) and (111) adjoining surfaces as well as the higher ratio of the ambient exposure area to the oxide/silicon interfacial area [40]. The differences in the activation energies of Si NW in the high and low temperatures reveal different oxidation kinetic mechanisms. At low temperatures, increases in the total oxide intensity are accompanied by a rise in the suboxide intensity with amounts comparable to the intensity of $\mathrm{SiO}_{2}$. Backbond oxidation can be considered as the primary mechanism causing 
the formation of $\mathrm{Si}-\mathrm{O}-\mathrm{Si}$ bonds below the surface-terminated $\mathrm{Si}-\mathrm{H}$ bonds. The backbonds can be oxidized in different oxidation states and can finally form the full oxide layer atop. Compared to planar samples, Si NWs exhibit a more rapid backbond oxidation, indicating the effect of circumferential tensile stresses on the stability of $\mathrm{Si}-\mathrm{Si}$ bonds. For longer oxidation times, an increased number of oxidized backbonds form and isolated $\mathrm{Si}$ $\mathrm{OH}$ bonds begin to form upon interaction of the $\mathrm{Si}-\mathrm{H}$ and $\mathrm{Si}-\mathrm{O}$ bonds with oxidized backbonds [41]. In this regime, the surface energy also takes on a role, which may explain the suppression of the oxidation level compared to the $2 \mathrm{D}$ case. By completion of the backbond oxidation, remaining $\mathrm{Si}-\mathrm{H}$ surface bonds start to rupture and hydrogen propagation begins. The low-temperature oxidation mechanism is summarized in the scheme illustrated in Figure 9. It should be noted that the hydroxyl groups shown in Figure 9 represent both the isolated hydroxyl groups formed throughout the oxidation and the isolated hydroxyl groups formed after the completion of oxidation, as is frequent for $\mathrm{SiO}_{2}$ in $\mathrm{H}_{2} \mathrm{O}$-containing environments [42].

At high temperatures, the retarded oxidation in $\mathrm{Si} \mathrm{NWs,} \mathrm{in}$ analogy with planar silicon, can be attributed to the self-limited oxidation caused by the function of the initially-formed oxide layer as a diffusion barrier. The two mechanisms are summarized in Figure 10.

It is crucial to study the oxidative behavior of organic molecules to deduce their impact on Si NW oxidation resistance. Specifically, low temperatures (below $200{ }^{\circ} \mathrm{C}$ ) are the main interest of this study, since almost all electronic devices are operated in this range.

\section{Si2p emission}

Before chemical treatment, Si NWs show a native oxide as illustrated previously in Figure 6. The oxide layer can be detected by XPS of the oxide core level spectrum. The Si2p of the oxide peak appears in the 101-104 eV binding energy range. In order to
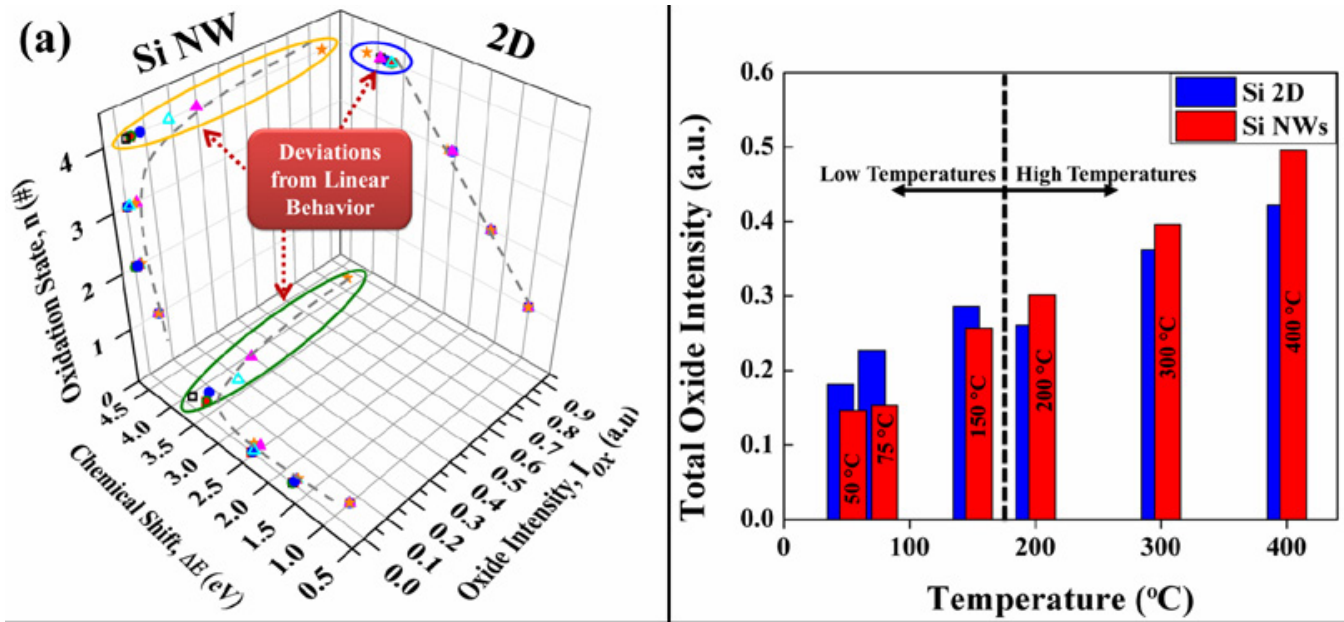

(b)

Figure 8. (a) The sub and full oxide distribution as function of binding energy shift and intensity per sub oxide on Si NWs and 2D, (b) total oxide intensity of all oxide states in low and high temperature in Si NWs and 2D surafces.

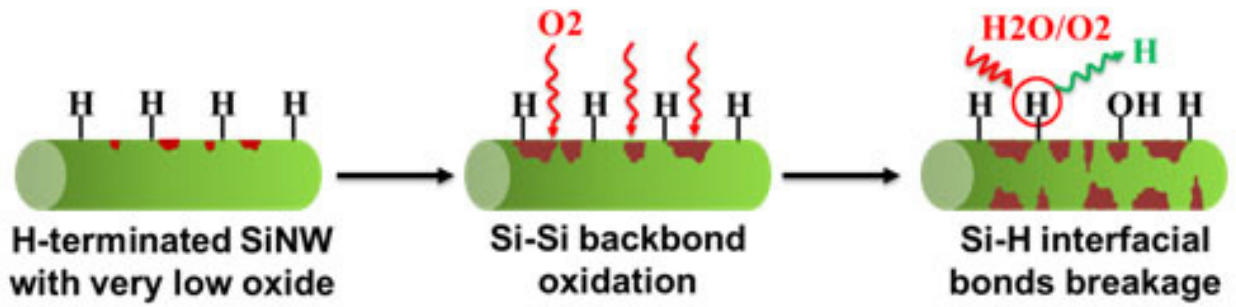

Figure 9. Scheme of the suggested mechanism for low-temperature oxidation of the H-terminated Si NW.

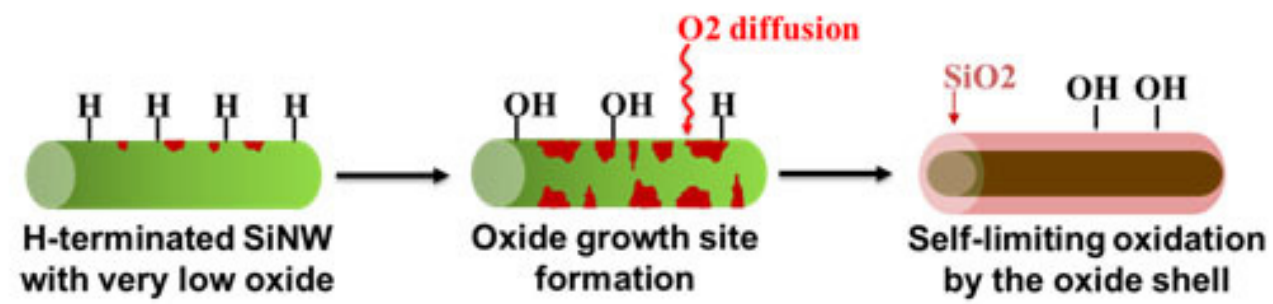

Figure 10. Scheme of the suggested mechanism for high-temperature oxidation of the $\mathrm{H}$-terminated Si NW. 
attach molecules to the Si NW surface, the native oxide should be removed. The removal of oxides confirmed by the absence of any peak in the range of 101-104 eV as can be clearly seen in Figure 11.

It should be noted that the $\mathrm{Si} 2 \mathrm{p}$ emission spectra of $\mathrm{SiO}_{2}-$ Si NW is shifted towards higher binding energy, which will be explained in the solar cell section.

\section{Carbon 1S emission:}

The emission of the $\mathrm{C} 1 \mathrm{~s}$ regime before and after termination is compared in order to describe the covalent attachment of the molecules to the surfaces. When comparing the two emissions, an additional peak must be introduced for molecule-terminated Si NW surfaces to obtain an appropriate deconvolution (Figure 12). Figure 12 depicts a XPS spectrum of C1s emission region for the methyl-terminated Si NWs. Before termination, the $\mathrm{C} 1 \mathrm{~s}$ spectrum was fitted to two $\mathrm{C}-\mathrm{C}$ at $285.20 \pm 0.02 \mathrm{eV}$, and $\mathrm{C}-\mathrm{O}$ at $286.69 \pm 0.02 \mathrm{eV}$. It is reasonable to assume that these adventitious hydrocarbons $(\mathrm{C}-\mathrm{O})$ could stem from wet chemical processing with a THF/methanol rinse before functionalization, and/or carbonaceous materials present in the laboratory environment. After termination, the alkyl-Si NW was fitted to three peaks: C-Si at284.11 $\pm 0.02 \mathrm{eV}, \mathrm{C}-\mathrm{C}$ at $285.20 \pm 0.02 \mathrm{eV}$ and $\mathrm{C}-\mathrm{O}$ at $286.69 \pm 0.02 \mathrm{eV}$. The new peak at $\mathrm{C}-\mathrm{Si}$ at $284.11 \pm 0.02$ $\mathrm{eV}$ confirms the chemical bonding of organic molecules onto the Si NW surface. Peaks were typically adjusted to produce fits that minimized the difference between the full widths at half-maximum. The center-to-center distances were fixed at $1.10 \pm 0.10 \mathrm{eV}$ between the $\mathrm{C}-\mathrm{Si}$ and $\mathrm{C}-\mathrm{C}$ emissions and at $2.60 \pm 0.10 \mathrm{eV}$ between the $\mathrm{C}-\mathrm{O}$ and C-Si emissions [27].

\section{How to Calculates the Coverage of the molecules on the Si NW Surface?}

Methyl (i.e. $\mathrm{CH}_{3}$ ) is the smallest organic alkyl molecule with a van der Waals diameter (VDW) of $2.5 \AA$, which is smaller than the internuclear distance between adjacent Si toms (3.8 $\AA$ ), and thus, nearly full surface coverage is possible (See Figure 13). To obtain the molecular coverage of surface atomic sites, the area under the C-Si peak is divided by the area under the Si2p peak (sum of $S i 2 p_{1 / 2}$ and $S i 2 p_{3 / 2}$ ) and normalized by the scan time. The coverage of the alkyl functionalities was compared with the highest value obtained for methyl $\left(C_{1}\right)$ functionality; in this instance "highest" means nearly full coverage of the $\mathrm{Si}$ atop sites, achieved after alkylation times of $>24 \mathrm{~h}$. This comparison is expressed throughout the text as "(C-Si/Si2p $)_{\text {alkyl }} /(\mathrm{C}-\mathrm{Si} / \mathrm{Si} 2 \mathrm{p})_{\text {max.methyl". }}$.

\section{Termination the Si NW with different Alkyl molecules}

The concentration of the molecules on the Si NW (i.e. coverage) was found to be dependent on steric effects caused by the lateral interactions between the terminating molecules on the surfaces. Steric effects and respective VDW diameter can hinder the formation of dense packing alkyls longer than methyl (i.e. $C_{1}$ ).

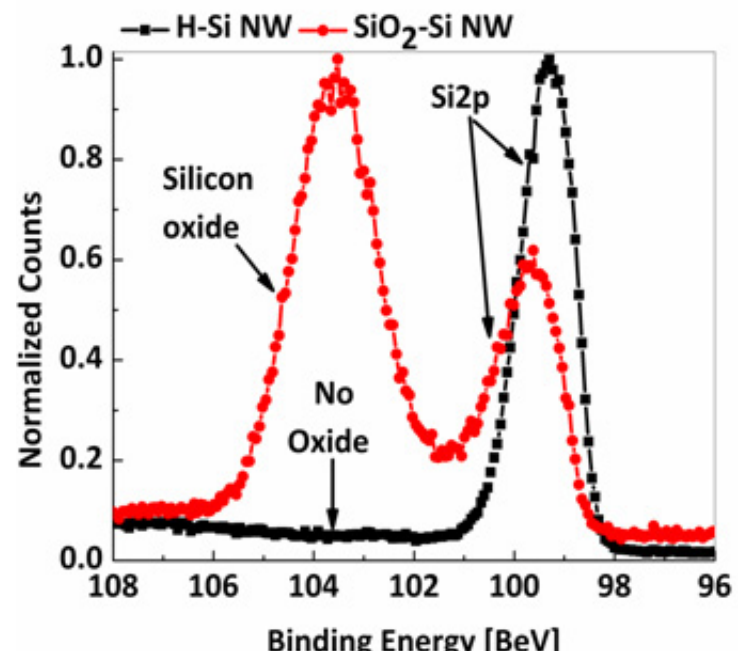

Figure 11. Si2p emission of $\mathrm{SiO}_{2}-\mathrm{Si} N W$ and $\mathrm{H}$-Si NW.
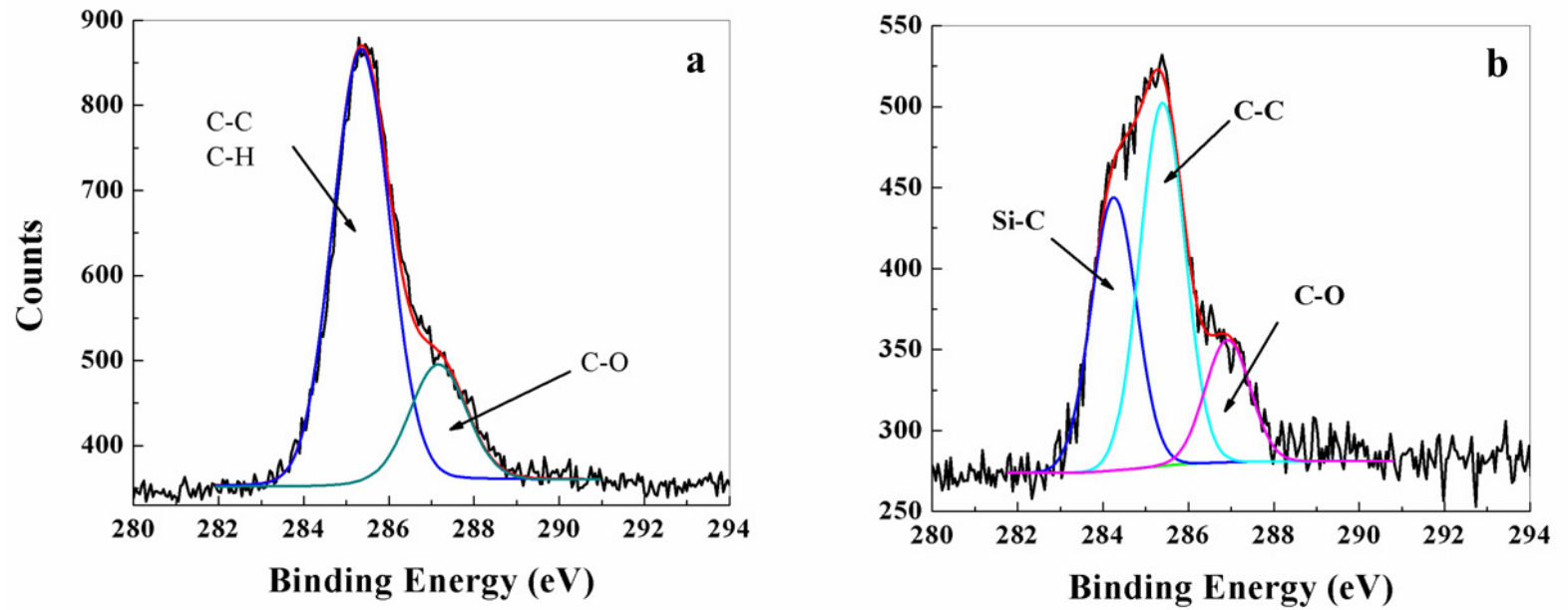

Figure 12. XPS data from the C1s emission region before and after alkyl-terminated Si NWs. (a) H-Si NWs show two peaks: C-C at 285.20 $\pm 0.02 \mathrm{eV}$, and $\mathrm{C}-\mathrm{O}$ at $286.69 \pm 0.02 \mathrm{eV}$. (b) Methyl-Si NWs, show three peaks: C-Si at 284.11 $\pm 0.02 \mathrm{eV}, \mathrm{C}-\mathrm{C}$ at $285.20 \pm 0.02 \mathrm{eV}$, and C-O at $286.69 \pm 0.02 \mathrm{eV}$. 
NOTE: $\mathrm{C}_{2} \mathrm{H}_{2} n_{+1}$ (where $n=1-10$ ) is represented by $\mathrm{C} n$. Therefore, methyl and decyl are represented by $C_{1}$ and $C_{10}$, respectively. Increasing the length of the alkyl chains increases the VDW diameter from $2.5 \AA$, in the case of $\mathrm{C}_{1}$, to more than 4.5-5.0 $\AA$ for longer alkyl chains, as in the case of $\mathrm{C}_{2}-\mathrm{C}_{5}$. As the VDW diameter increases, low dense molecules are expected to connect to $\mathrm{Si}$ NW and limit the coverage to a maximum value of $50-55 \%$ as illustrated in Figure 14.

With these findings in mind, it found the chain length dependence in Figure 14 to be consistent with the similar decay of the coverage reported by others on flat $\mathrm{Si}(111)$ surfaces for longer chains than in the present work, with no increase in coverage above 7 carbon atoms. Based on these inconsistencies it can be inferred that the higher coverage obtained for $>\mathrm{C}_{6}$ chain lengths is artificial and/or not significant owing to problems in fitting the XPS data. In contrast, a few experimental observations suggest that the coverage behavior of chains longer than $\mathrm{C}_{6}$ on $\mathrm{Si}$ NWs might not be artificial: (1) ToF SIMS experiments (which eliminate potential artificial observations) have shown higher absolute coverage on long chain lengths, in good consistency with XPS observations. (2) In the case of $2 \mathrm{D} \mathrm{Si}(100)$ surface, the results of ToF-SIMS have shown (more or less) the expected coverage versus chain length behavior; at the time, similar behavior was not observed in the case of Si NWs. (3) The experimental error and/or accuracy of the peak fittings are relatively small (4-11\%). It is reasonable to consider the passivation of Si NWs by alkyl molecules to be a function of two main factors: (I) moleculemolecule lateral interaction and (II) molecule-substrate vertical interaction. For short alkyl chains $\left(\mathrm{C}_{1}-\mathrm{C}_{5}\right)$, which exhibit liquidlike behavior and thermal fluctuations, the determining factor is the vertical interaction [43]. Increasing the chain length to $\mathrm{C}_{6}-\mathrm{C}_{10}$ forms a solid-like phase, where the lateral interactions become dominant in the consequent coverage of the Si NW surfaces. It is worth pointing out that the lateral interactions between long alkyl chains might be formed during the physisorption stage, before the covalent bindings between the carbon and silicon atoms (or chemisorption) arise [44].

\section{Stability of functionalized Si NW}

The stability of Si NWs functionalized by organic molecules is affected by the molecular chain length, coverage level, surface energy and diameter. The stability plays a large role in the oxidation process. We will discuss these parameters here.

Effect of coverage and chain length: The atomic sites not connected to the alkyl chains, which are known as atomic pinholes, determine the susceptibility of the surfaces to

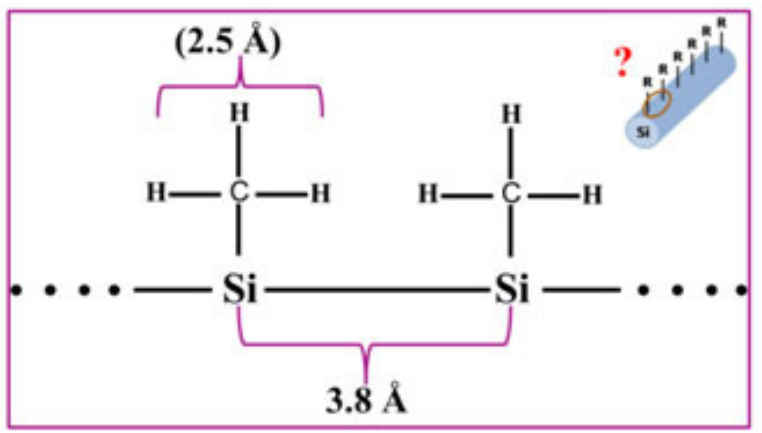

Figure 13. Schematic diagram of methyl connected to adjacent Si atoms.

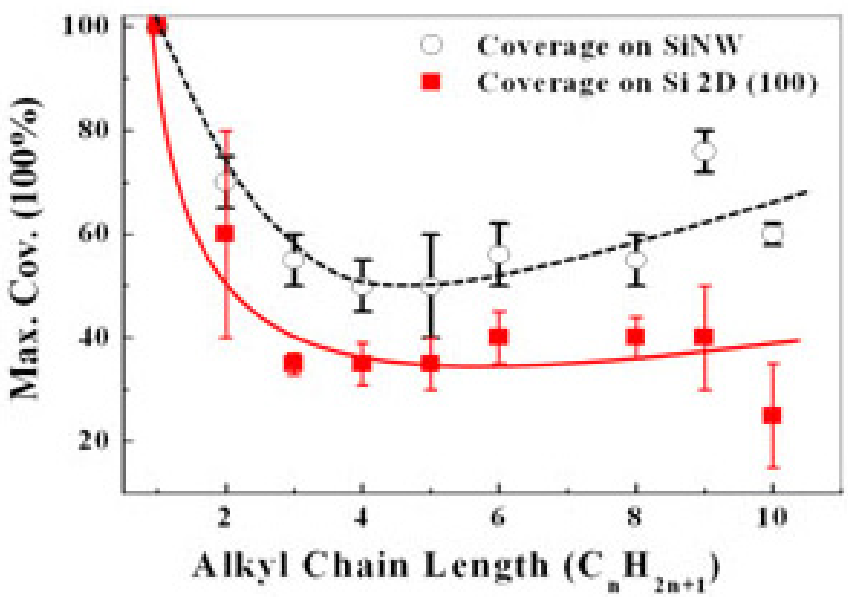

Figure 14. Гmax-alkyl versus alkyl chain length on Si NWs and, for comparison, on 2D Si(100) surfaces. Note: Гmax-alkyl) (C-Si/Si2p)max-alkyl/(C-Sil Si2p)max-C1. Reproduced with permission from ref [28]. 
interaction with oxidants $\left(\mathrm{O}_{2}\right.$ and/or $\left.\mathrm{H}_{2} \mathrm{O}\right)$. To investigate the effect of the coverage and chain length, freshly-prepared alkylated Si NW functionalities were exposed to ambient air for several hundred hours, as shown in Figure 15. All the alkylated Si NW show high oxide resistivity in the first 2 to 3 days of the experiment, but the oxide intensity became considerable after 8 days exposure to air, depended on the chain length and coverage level. For example, after 336 hours of exposure, the $\mathrm{C}_{1}$ (showing $100 \%$ coverage) oxide intensity reached 0.03 . However, for the same oxidation period, when the coverage decreased to $50 \%$ as in case of $\mathrm{C}_{3}$ to $\mathrm{C}_{6}$, the oxide level rose to $\sim$ 0.13. This implies that $\mathrm{Si}$ NWs terminated with $\mathrm{C}_{3}-\mathrm{C}_{6}$ alkyl molecules exhibit less stability against oxidation compared to $\mathrm{C}_{1}$, which show about 2-fold higher oxidation resistance than that of $\mathrm{C}_{3}-\mathrm{C}_{6}-\mathrm{Si}$ NWs. Nevertheless, when the molecules have the same coverage, as in case of $\mathrm{C}_{3}-\mathrm{C}_{6}$, the observations can be explained by the fact that shorter molecules have a lower oxidation resistance. Decreasing the coverage below $50 \%$, (as in case on $\mathrm{C}_{10}$ ), decreases the oxidation stability one fold relative to $\mathrm{C}_{3}-\mathrm{C}_{6}$ molecules and 3-4 fold relative to $C_{1}$ [28].

Effect of surface energy and diameter: To understand the effect of the surface energy and diameter, methyl groups were terminated onto four surfaces: 2D (100), 2D (111), Si NW 50nm in diameter (Si NW ${ }_{50 \mathrm{~nm}}$ ) and Si NW 25nm in diameter (Si NW $25 \mathrm{~nm}$ ). Then, all samples were exposed to ambient air for long periods of time. As shown in Figure 16, the stability of methyl groups on Si NW is higher than the stability on planar Si of either the (100) or (111) configuration. After 336 h, NWs show ca.3-fold lower oxidation intensity than the equivalent planar Si surfaces, despite similar initial coverage levels. These observations can be attributed to the stronger $\mathrm{Si}-\mathrm{C}$ bonds on Si NW surfaces and are supported by the shift in the Si-C bond binding energy from $284.33 \pm 0.02 \mathrm{eV}\left(\mathrm{Si} \mathrm{NW}_{25 \mathrm{~nm}}\right), 284.22 \pm 0.02 \mathrm{eV}\left(\mathrm{Si} \mathrm{NW}_{50 \mathrm{~nm}}\right)$ to $284.11 \pm 0.02 \mathrm{eV}$ for planar $2 \mathrm{D} \mathrm{Si}$. The stronger bond in Si NW is attributed to the higher surface energy in Si NW relative to $2 \mathrm{D}$ surfaces. The $\sim 0.11 \pm 0.02 \mathrm{eV}$ higher binding energy observed for $\mathrm{CH}_{3}-\mathrm{Si} \mathrm{NW}$, compared to equivalent planar $\mathrm{CH}_{3}-\mathrm{Si}(100)$ and (111) surfaces, can further be ascribed to the higher reactivity of atop sites. Interestingly, $\mathrm{CH}_{3}-\mathrm{Si} \mathrm{NW}_{50 \mathrm{~nm}}$ surfaces exhibits a higher stability against oxidation than equivalent $\mathrm{CH}_{3}-\mathrm{Si}$ $\mathrm{NW}_{25 \mathrm{~nm}}$ surfaces, even though it has a lower binding energy. The higher oxide intensity can be attributed to the diffusion of gold nanoparticles along and inside the Si $\mathrm{NW}_{25 \mathrm{~nm}}$. The $\mathrm{Au}$ nanoparticles from the catalyst are very mobile and diffuse over the Si NW surfaces (and inside the bulk regime). This effect is enhanced in thin NWs and, as described in our previous report, nanoparticles can accelerate the oxidation on NWs [45]. The higher stability of the $2 \mathrm{D}(111)$ relative to the $2 \mathrm{D}(100)$ structure is understandable since it naturally has a $15-20 \%$ higher coverage than the $2 \mathrm{D}(100)$ case [46].

Effect of Bonds type: $\pi-\pi$ vs. $\sigma-\sigma$ Interactions: The stability of the Si NW surfaces has been found to be affected by the $\pi-\pi$ vs. $\sigma-\sigma$ interaction. Si NW were embedded with methyl $\mathrm{CH}_{3}$ and propenyl $\left(\mathrm{CH}_{3}-\mathrm{CH}=\mathrm{CH}-\right)$. As shown in Figure 17, the oxidation of $\mathrm{CH}_{3}-\mathrm{CH}=\mathrm{CH}-\mathrm{Si}$ and $\mathrm{CH}_{3}-\mathrm{Si}$ NWs began after only $\sim 100 \mathrm{~h}$ of exposure and the process was more stable in the presence of propynyl.

After $180 \mathrm{hr}, \mathrm{CH}_{3}-\mathrm{CH}=\mathrm{CH}-\mathrm{Si}$ show an oxide intensity of $0.015 \pm 0.005$ that was almost half of the $0.036 \pm 0.012$ oxide intensity of $\mathrm{SiO}_{2} / \mathrm{Si} 2 \mathrm{p}$, which obtained after $720 \mathrm{~h}$. In contrast, the oxidation of $\mathrm{CH}_{3}$-Si NWs continuously increased after $100 \mathrm{~h}$ of exposure, reaching $0.11 \pm 0.017$ after $\sim 720 \mathrm{~h}$, without showing any indication of termination. The high stability of the $\mathrm{CH}_{3}-$ $\mathrm{CH}=\mathrm{CH}-\mathrm{Si}$ NW can be attributed to the $\pi-\pi$ interactions between the adjacent molecules [47-49].

\section{Integration of hybrid Si NW into Solar Cells}

Analysis suggests that extrinsic effects (i.e. surface states and surface charge) accompanied by the adsorption of molecular layers significantly affect solar cell characteristics. Three different surface terminations of Si NWs are presented to the discussion: (i) $\mathrm{H}-\mathrm{Si} \mathrm{NWs}$ for which the oxide shell was removed by a standard $\mathrm{HF}$ dip, (ii) $\mathrm{SiO}_{2}-\mathrm{Si} \mathrm{NWs}$ with a single monolayer of oxide grown after the HF dip (14 days); (iii) $\mathrm{CH}_{3}$-Si NW samples, which were further processed by methyl functionalization immediately after

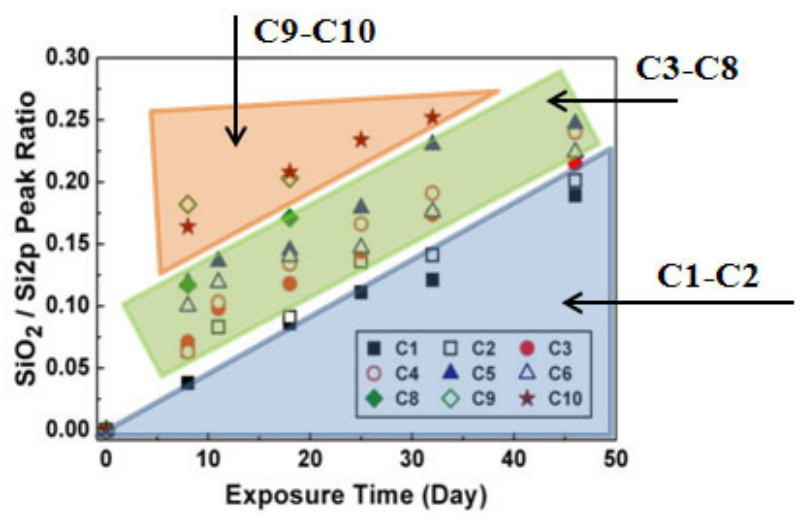

Figure 15. Observed oxidation intensity $\left(\mathrm{SiO}_{2} / \mathrm{Si} 2 \mathrm{p}\right.$ peak ratio) of alkylterminated Si NWs at different exposure times to ambient air. Reproduced with permission from ref [28].

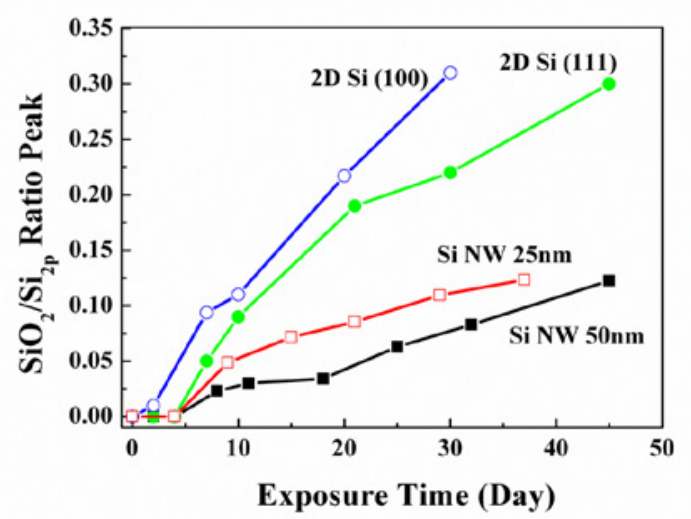

Figure 16. Ratio of the oxidized Si2p peak area to the bulk Si2p peak area for the methyl modification of $N W_{25 \mathrm{~nm}}$ and $N W_{50 \mathrm{~nm}}$ and $2 D$ $\mathrm{Si}(111)$, exposed to air over extended time periods. 
the HF dip. The surface Fermi level was calculated from the emission of the Si2p yields, namely $0.83 \mathrm{eV}, 0.98 \mathrm{eV}$ and $1.05 \mathrm{eV}$ for $\mathrm{CH}_{3}$-Si NW, $\mathrm{H}-\mathrm{SiNW}$ and $\mathrm{SiO}_{2}$-Si NW, respectively. The work function of all the samples was measured independently by the Kelvin probe method as $\Phi_{\mathrm{SiO}-\mathrm{Si} \mathrm{NW}}=4.32 \mathrm{eV}, \Phi_{\mathrm{H}-\mathrm{Si} \mathrm{NW}}=4.26 \mathrm{eV}$, $\Phi_{\mathrm{CH} 3 \mathrm{Si} \mathrm{NW}}=4.22 \mathrm{eV}$. Combining these data with the Fermi level position relative to the band edges $\left(\mathrm{E}_{\mathrm{F}}-\mathrm{E}_{\mathrm{v}}\right)$, yields electron affinity values $(\chi)$ of $4.29 \mathrm{eV}, 4.12 \mathrm{eV}$ and $3.93 \mathrm{eV}$ for $\mathrm{SiO}_{2}-\mathrm{Si} \mathrm{NW}, \mathrm{H}-\mathrm{Si}$ NW and $\mathrm{CH}_{3}-\mathrm{Si} \mathrm{NW}$, respectively, according to $\chi=\Phi-\mathrm{E}_{\mathrm{g}}+\left(\mathrm{E}_{\mathrm{F}}-\mathrm{E}_{\mathrm{V}}\right)$. The bulk Fermi level position was obtained from the specific resistance $(1-5 \Omega \mathrm{cm})$ of the n-type samples and gave $E_{F}$ $E_{v}=0.88 \pm 0.02 \mathrm{eV}$. Slight upward band bending of $0.05 \mathrm{eV}$, which is consistent with flat band conditions in the case of $\mathrm{CH}_{3}-\mathrm{Si} \mathrm{NW}$ sample; and downward band bending corresponded to electron accumulation at the surface of the $\mathrm{H}-\mathrm{Si} \mathrm{NW}$ and $\mathrm{SiO}_{2}-\mathrm{Si} \mathrm{NW}$. This uncommon aspect clearly indicates a, yet unidentified, surface doping process supporting the n-type character. With $E_{g}=1.12$ $\mathrm{eV}$, and estimating the electron affinity of the bulk silicon as 4.05 $\mathrm{eV}$, the surface dipoles, $\delta_{\mathrm{ss}}$, caused by the different monolayer surfaces were calculated to be $+0.24 \mathrm{eV},+0.07 \mathrm{eV}$ and $-0.12 \mathrm{eV}$ for $\mathrm{SiO}_{2}-\mathrm{Si} \mathrm{NW}, \mathrm{H}-\mathrm{Si} \mathrm{NW}$ and $\mathrm{CH}_{3}$-Si NW respectively [50].

Photoelectron Yield Spectroscopy of the Solar Cell heterojunction: The degree of surface band bending provides a measure for the quality of the electronic passivation on a semiconductor surface. The improved electronic properties of the interface directly influence the photoemission of electrons. The photoelectron yield spectra of the three different NW samples investigated in this work are shown in Figure 18. Each PY spectrum shows two thresholds near $5.0 \pm 0.2 \mathrm{eV}$ and $4.2 \pm 0.2 \mathrm{eV}$. The higher energy band corresponds to the valence band density of states of the silicon while the lower energy band is associated with defects in the band gap. These spectra essentially represent the occupied density of states. The band edges of the two emissions were plotted by dashed lines as can be seen in Figure 18.

The spectra are further normalized at $0.76 \mathrm{eV}$ below the valence band maximum where they should be strongly dominated by the valence band emission only and thus, the PYS should be identical for all the three samples at this energy point; the highest defect density is seen for the $\mathrm{SiO}_{2}-\mathrm{Si} \mathrm{NWs}$. In the case of the $\mathrm{H}-\mathrm{Si} \mathrm{NW}$, the defect band is already lower by a factor of about 2. Finally, the lowest defect density is observed for the $\mathrm{CH}_{3}-\mathrm{Si}$ NWs, which show an additional band between 4.7 and $5.3 \mathrm{eV}$, which is presumably related to the methyl functionalization.

I-V curves of solar cells processed with functionalized $\mathrm{Si}$ NWs: Si NWs were employed to assemble the photovoltaic cells together with polymer. Bashouti and co-works demonstrate a hybrid organic / inorganic solar cell based on a combination of a polymer (PEDOT:PSS) constituting the hole conductor and $\mathrm{Si}$ NW play the role of light absorber and electron conductor [9]. These $\mathrm{Si} N \mathrm{NW}$ surfaces were terminated by $\mathrm{SiO}_{2}$ and $\mathrm{CH}_{3}$ and integrated into a solar cell through identical processes. In all the cells, the photogenerated electron-hole pairs are separated at a heterojunction forming at the Si NW/polymer interface as shown in Figure 19.
This Si NW-based cell concept has the following advantages: (i) efficient light absorption (ii) short diffusion distance of carriers to the wrapped around heterojunction [51,52]; (iii) use of the air-stable and robust polymer, PEDOT:PSS, as an efficient hole conductor [9]; (iv) the Si NW/polymer solar cell design utilizes only $1 \%$ of the Si used in other thin film cells of identical thickness. However, for photovoltaic applications, full coverage of Si NWs by PEDOT:PSS is desirable but has not, as of yet, been achieved. Figure 20 shows the current-voltage (I-V) characteristics of $\mathrm{CH}_{3}$-SiNW/PEDOT:PSS and $\mathrm{SiO}_{2}-\mathrm{Si} \mathrm{NW} /$ PEDOT:PSS solar cells under AM1.5 illumination. $\mathrm{SiO}_{2}-\mathrm{SiNW} /$ PEDOT:PSS samples can withstand a short circuit current (Jsc) of $1.6 \mathrm{~mA} / \mathrm{cm}^{2}$, an open circuit voltage (Voc) of $320 \mathrm{mV}$, a fill factor (FF) of 0.53 and a conversion efficiency $(\mu)$ of $0.28 \% . \mathrm{CH}_{3}-\mathrm{Si}$ NW/PEDO T:PSS devices exhibit improved performance with Jsc, Voc, FF and $\mu$ magnitudes of $7.0 \mathrm{~mA} / \mathrm{cm}^{2}, 399 \mathrm{mV}, 0.44$ and $1.2 \%$, respectively. The low values of FF and JsC in both

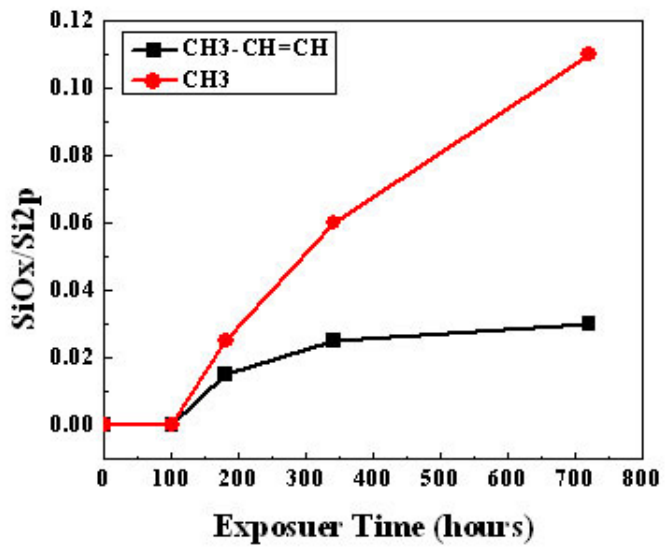

Figure 17. Ratio of the $\mathrm{SiO}_{2}$ to Si2p peak areas for the different surface modifications of Si NWs, exposed to air over extended time periods. Reproduced with permission from ref [47].

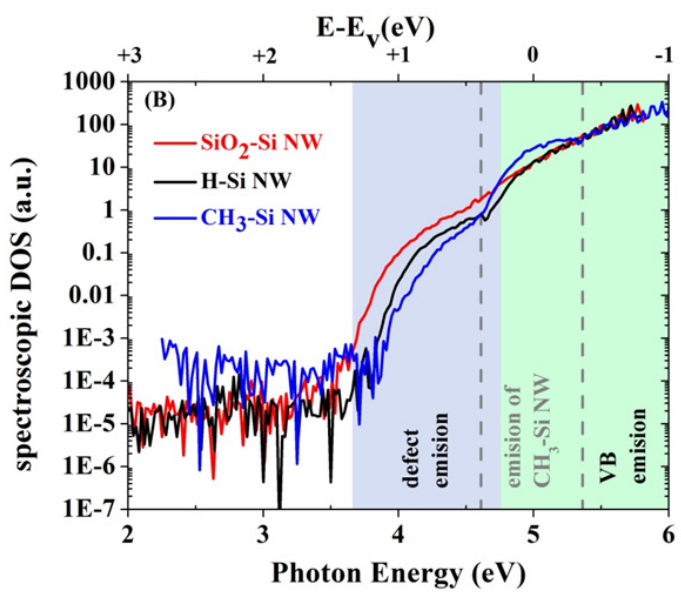

Figure 18. Photoelectron yield $Y(h v)$ spectral and spectral density of states of $\mathrm{SiO}_{2}-\mathrm{Si} \mathrm{NW}, \mathrm{H}-\mathrm{Si} \mathrm{NW}$ and $\mathrm{CH}_{3}-\mathrm{Si} \mathrm{NW}$. Reproduced with permission from ref [38]. 
types of samples are attributed to high contact resistances (Rs $300 \Omega$ ). It should be noted that by decreasing the resistance, the efficiency of the solar cell can be improved. In spite of notably low efficiencies of Si NW relative to the values commonly reported for efficient solar cells, the comparative increase in efficiency (by about a factor of 4) upon methylation proves that this kind of surface functionalization has very promising prospective.

The improved performance of the $\mathrm{CH}_{3}$-Si NWs is attributed to the removal of the tunnelling oxide and the reduction of defect states related to PY, which is caused by a reduced defect density at the heterojunction interface. Using one monolayer of $\mathrm{CH}_{3}$ at the interface allows for a more efficient charge coupling between silicon and the polymer. By reducing the defect density of $\mathrm{CH}_{3}-$ Si NWs, the surface recombination is decreased, causing an increase in Voc. According to the Shockley diode equation $V o c=$ $k B T / q \cdot \ln (J s c / J O)$, where $J O$ is the saturation current and the other variables have their usual meanings. Since an increase of Jsc influences $V o c$ as well, it must be mentioned that the Voc gain observed cannot be explained by this effect alone. Assuming a similar $\mathrm{JO}$, which correspond to the removal of the tunneling oxide without changing the interface properties, the increase of Jsc would lead to a Voc gain of $\Delta V o c=k T / q . I n(J s c$, methyl/ Jsc, oxide $)=k B T / q \cdot \ln (7.0 / 1.6)=0.037 \mathrm{~V}$. Regarding the observed gain of $\Delta V o c=0.079 \mathrm{~V}$, only a reduced surface recombination's (as measured by PY) and/or a favorable barrier formations (surface dipole) can establish consistency with the experimental data. The well passivation of methyl groups showed an impact in different devices as reported by Lewis as well [22,53,54].

\section{Conclusions}

Si NWs were functionalized by different organic compounds through a two-step chlorination/alkylation process. Methyl provided the highest coverage of all of the alkyl molecules. Increasing the chain length decreased the coverage to $50-70 \%$.
Molecules with double bonds such as propenyl $(-\mathrm{CH}=\mathrm{CH}-$ $\mathrm{CH}_{3}$ ) showed excellent surface passivation, with a very small amount of silicon oxide forming after more than two months of exposure to ambient air, which was attributed to the $\pi-\pi$ interaction. The thermal stabilities of the organically-tailored $\mathrm{Si}$ NWs are dependent on the molecular coverage, chain length, types of bond interaction, $\pi-\pi$ or $\sigma-\sigma$ interactions, surface energy and Si NW diameter. Studies on the H-terminated $\mathrm{Si}$ NW oxidation kinetics revealed that their thermal stability relies strongly on the temperature. At lower temperatures, initially Si$\mathrm{Si}$ backbond oxidation and later $\mathrm{Si}-\mathrm{H}$ bond propagation are the rate-determining steps. At higher temperatures, oxygen diffusion is considered to be the initial rate-determining step, as it controls the growth site concentration.

The oxide free surfaces are important and necessary in many technological aspects, e.g. radial epitaxy on NWs to realize vertical P-N junctions in photovoltaics or radial Si super-lattices

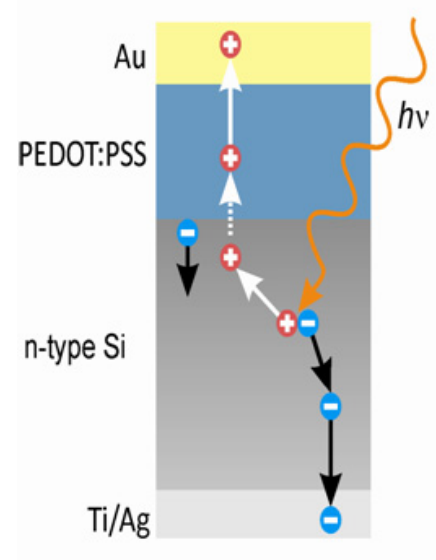

\section{PEDOT:PSS n-type Si}

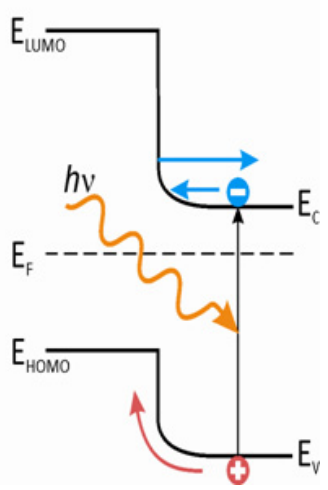

Figure 19. Schematic diagram shows the charge separation near the Si/ polymer interface.
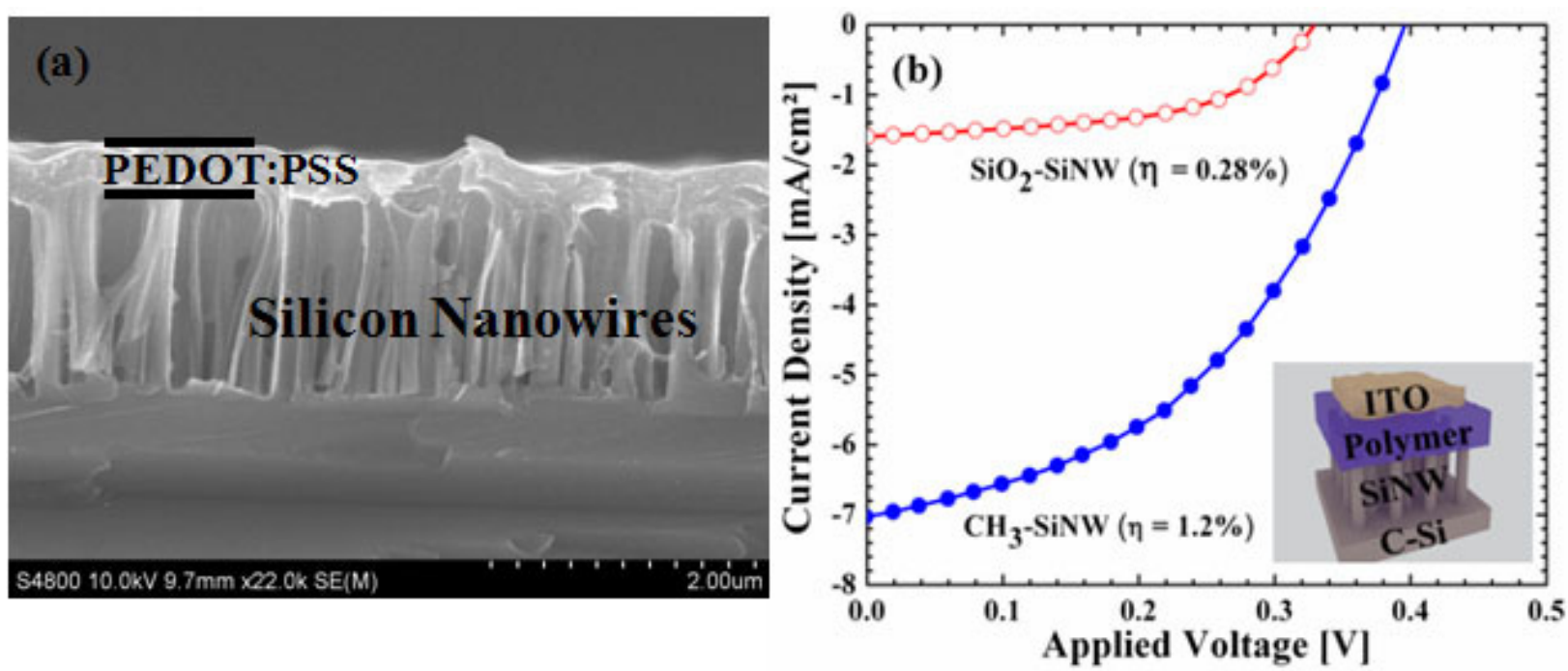

Figure 20. (a) Tilted view of the heterojunction Si NWIPEDOT:PSS. (b) J-V characteristic under AM1.5 illuminations of the radial heterojunction solar cells from $\mathrm{CH}_{3}-\mathrm{NWs}$ and $\mathrm{SiO}_{2}-\mathrm{NWs}$. Inset: schematic view of a solar cell device structure. 
in optoelectronics. Hybrid Si NWs have already been integrated in solar cells in order to utilize their advantages. Several fundamental surface properties relevant to solar cells have been found to be strongly dependent on the type of functionalization used. Thus, the right choice of surface modification is crucial to solar cell performance. For instance, Si NW attached to $\mathrm{CH}_{3}, \mathrm{H}$ or oxide groups produce a core-level shift and band bending in the $\mathrm{Si} 2 \mathrm{p}$ emission derived from the $\mathrm{Si}$ surface atoms at $50 \mathrm{meV}$, $100 \mathrm{meV}$ and $170 \mathrm{meV}$, respectively. The good passivation of $\mathrm{CH}_{3}$ on the Si NW reduces the density of states and create a negative dipole $(-0.12 \mathrm{eV})$, which lowers the vacuum level and thereby increases the yield. Hydrogen- and $\mathrm{SiO}_{2}$-terminated NWs demonstrate enhanced vacuum levels and an increased surface density. As a result, solar cells with $\mathrm{CH}_{3}$-based radial heterojunctions demonstrate better performance and efficiencies

References

[1] E. Lifshitz, M. Bashouti, V. Kloper, A. Kigel, M.S. Eisen, S. Berger, Synthesis and characterization of PbSe quantum wires, multipods, quantum rods,and cubes, Nano Lett, 3 (2003) 857-862.

[2] K.S. Leschkies, R. Divakar, J. Basu, E. Enache-Pommer, J.E. Boercker, C.B. Carter, U.R. Kortshagen, D.J. Norris, E.S. Aydil, Photosensitization of $\mathrm{ZnO}$ nanowires with $\mathrm{CdSe}$ quantum dots for photovoltaic devices, Nano Lett, 7 (2007) 1793-1798

[3] M.Y. Bashouti, R.T. Tung, H. Haick, Tuning the Electrical Properties of $\mathrm{Si}$ Nanowire Field-Effect Transistors by Molecular Engineering, Small, 5 (2009) 2761-2769.

[4] S.W. Schmitt, F. Schechtel, D. Amkreutz, M. Bashouti, S.K Srivastava, B. Hoffmann, C. Dieker, E. Spiecker, B. Rech, S.H. Christiansen, Nanowire Arrays in Multicrystalline Silicon Thin Films on Glass: A Promising Material for Research and Applications in Nanotechnology, Nano Lett, 12 (2012) 40504054.

[5] V. Sivakov, G. Andra, A. Gawlik, A. Berger, J. Plentz, F. Falk, S.H. Christiansen, Silicon Nanowire-Based Solar Cells on Glass: Synthesis, Optical Properties, and Cell Parameters, Nano Lett, 9 (2009) 1549-1554.

[6] M.D. Kelzenberg, D.B. Turner-Evans, B.M. Kayes, M.A. Filler, M.C. Putnam, N.S. Lewis, H.A. Atwater, Photovoltaic measurements in single-nanowire silicon solar cells, Nano Lett, 8 (2008) 710-714.

[7] M.D. Kelzenberg, D.B. Turner-Evans, M.C. Putnam, S.W. Boettcher, R.M. Briggs, J.Y. Baek, N.S. Lewis, H.A. Atwater, High-performance Si microwire photovoltaics, Energ Environ Sci, 4 (2011) 866-871

[8] S.K. Kim, R.W. Day, J.F. Cahoon, T.J. Kempa, K.D. Song, H.G. Park, C.M. Lieber, Tuning Light Absorption in Core/Shell Silicon Nanowire Photovoltaic Devices through Morphological Design, Nano Lett, 12 (2012) 4971-4976. up to four times than that of conventional cells: $\mathrm{SiO}_{2}-\mathrm{Si} \mathrm{NW} /$ PEDOT:PSS cells obey a short circuit current (Jsc) of $1.6 \mathrm{~mA} /$ $\mathrm{cm}^{2}$, an open circuit voltage (Voc) of $320 \mathrm{mV}$, a fill factor (FF) of 0.53 and a conversion efficiency $(\mu)$ of $0.28 \% . \mathrm{CH}_{3}-\mathrm{Si}$ NW/ PEDOT:PSS devices exhibit improved performance with values for Jsc, Voc, FF and $\mu$ of $7.0 \mathrm{~mA} / \mathrm{cm}^{2}, 399 \mathrm{mV}, 0.44$ and $1.2 \%$, respectively.

\section{Acknowledgments}

Authors acknowledge the financial support by the FP7 EU project LCAOS (nr. 258868, HEALTH priority), the NAWION project funded by German Ministry of research and education (BMBF). Ms. Heidemarie Embrechts's help with editing the manuscript is gratefully acknowledged.
[9] S. Kirchmeyer, K. Reuter, Scientific importance, properties and growing applications of poly( 3,4-ethylenedioxythiophene), J Mater Chem, 15 (2005) 2077-2088.

[10] C.Y. Kuo, C. Gau, B.T. Dai, Photovoltaic characteristics of silicon nanowire arrays synthesized by vapor-liquid-solid process, Sol Energ Mat Sol C, 95 (2011) 154-157.

[11] H.C. Lee, S.C. Wu, T.C. Yang, T.J. Yen, Efficiently Harvesting Sun Light for Silicon Solar Cells through Advanced Optical Couplers and A Radial p-n Junction Structure, Energies, 3 (2010) 784-U215

[12] Q.L. Li, X.X. Zhu, Y. Yang, D.E. Ioannou, H.D. Xiong, D.W. Kwon, J.S. Suehle, C.A. Richter, The large-scale integration of high-performance silicon nanowire field effect transistors, Nanotechnology, 20 (2009).

[13] C.X. Lin, M.L. Povinelli, Optical absorption enhancement in silicon nanowire arrays with a large lattice constant for photovoltaic applications, Opt Express, 17 (2009) 1937119381.

[14] C.W. Liu, C.L. Cheng, B.T. Dai, C.H. Yang, J.Y. Wang, Fabrication and Photovoltaic Characteristics of Coaxial Silicon Nanowire Solar Cells Prepared by Wet Chemical Etching, Int J Photoenergy, (2012).

[15] C. Chen, R. Jia, H.H. Yue, H.F. Li, X.Y. Liu, D.Q. Wu, W.C. Ding, T.C. Ye, S. Kasai, H. Tamotsu, J.H. Chu, S.L. Wang, Silicon nanowire-array-textured solar cells for photovoltaic application, J Appl Phys, 108 (2010).

[16] Y. Paska, H. Haick, Interactive Effect of Hysteresis and Surface Chemistry on Gated Silicon Nanowire Gas Sensors, Acs Appl Mater Inter, 4 (2012) 2604-2617.

[17] Y. Paska, T. Stelzner, O. Assad, U. Tisch, S. Christiansen, H. Haick, Molecular Gating of Silicon Nanowire Field-Effect Transistors with Nonpolar Analytes, Acs Nano, 6 (2012) 335345.

[18] Y. Paska, T. Stelzner, S. Christiansen, H. Haick, Enhanced Sensing of Nonpolar Volatile Organic Compounds by Silicon 
Nanowire Field Effect Transistors, Acs Nano, 5 (2011) 56205626.

[19] Y. Cui, Z.H. Zhong, D.L. Wang, W.U. Wang, C.M. Lieber, High performance silicon nanowire field effect transistors, Nano Lett, 3 (2003) 149-152.

[20] K.Q. Peng, J.S. Jie, W.J. Zhang, S.T. Lee, Silicon nanowires for rechargeable lithium-ion battery anodes, Appl Phys Lett, 93 (2008).

[21] R. Rurali, Colloquium: Structural, electronic, and transport properties of silicon nanowires, Rev Mod Phys, 82 (2010) 427-449.

[22] H. Haick, P.T. Hurley, A.I. Hochbaum, P.D. Yang, N.S. Lewis, Electrical characteristics and chemical stability of nonoxidized, methyl-terminated silicon nanowires, J Am Chem Soc, 128 (2006) 8990-8991.

[23] O. Shirak, O. Shtempluck, V. Kotchtakov, G. Bahir, Y.E. Yaish, High performance horizontal gate-all-around silicon nanowire field-effect transistors, Nanotechnology, 23 (2012).

[24] Q.K. Shu, J.Q. Wei, K.L. Wang, S.A. Song, N. Guo, Y. Jia, Z. Li, Y. Xu, A.Y. Cao, H.W. Zhu, D.H. Wu, Efficient energy conversion of nanotube/nanowire-based solar cells, Chem Commun, 46 (2010) 5533-5535.

[25] B. Eisenhawer, S. Sensfuss, V. Sivakov, M. Pietsch, G. Andra, F. Falk, Increasing the efficiency of polymer solar cells by silicon nanowires, Nanotechnology, 22 (2011).

[26] E.C. Garnett, P.D. Yang, Silicon nanowire radial p-n junction solar cells, J Am Chem Soc, 130 (2008) 9224-+.

[27] M.Y. Bashouti, T. Stelzner, A. Berger, S. Christiansen, H. Haick, Chemical Passivation of Silicon Nanowires with C(1)-C(6) Alkyl Chains through Covalent Si-C Bonds, J Phys Chem C, 112 (2008) 19168-19172.

[28] M.Y. Bashouti, T. Stelzner, S. Christiansen, H. Haick, Covalent Attachment of Alkyl Functionality to $50 \mathrm{~nm}$ Silicon Nanowires through a Chlorination/Alkylation Process, J Phys Chem C, 113 (2009) 14823-14828.

[29] J.S. Jie, W.J. Zhang, K.Q. Peng, G.D. Yuan, C.S. Lee, S.T. Lee, Surface-Dominated Transport Properties of Silicon Nanowires, Adv Funct Mater, 18 (2008) 3251-3257.

[30] J. Terry, M.R. Linford, C. Wigren, R.Y. Cao, P. Pianetta, C.E.D. Chidsey, Determination of the bonding of alkyl monolayers to the Si(111) surface using chemical-shift, scanned-energy photoelectron diffraction, Appl Phys Lett, 71 (1997) 10561058.

[31] F. Effenberger, G. Gotz, B. Bidlingmaier, M. Wezstein, Photoactivated preparation and patterning of self-assembled monolayers with 1-alkenes and aldehydes on silicon hydride surfaces, Angew Chem Int Edit, 37 (1998) 2462-2464.

[32] A.B. Sieval, R. Linke, G. Heij, G. Meijer, H. Zuilhof, E.J.R. Sudholter, Amino-terminated organic monolayers on hydrogen-terminated silicon surfaces, Langmuir, 17 (2001) 7554-7559.

[33] R.S. Wagner, W.C. Ellis, Vapor-Liquid-Solid Mechanism of Single Crystal Growth ( New Method Growth Catalysis from Impurity Whisker Epitaxial + Large Crystals Si E ), Appl Phys Lett, 4 (1964) 89-\&.
[34] A. Bansal, X.L. Li, S.I. Yi, W.H. Weinberg, N.S. Lewis, Spectroscopic studies of the modification of crystalline Si(111) surfaces with covalently-attached alkyl chains using a chlorination/alkylation method, J Phys Chem B, 105 (2001) 10266-10277.

[35] F.J. Himpsel, F.R. Mcfeely, A. Talebibrahimi, J.A. Yarmoff, G. Hollinger, Microscopic Structure of the Sio2/Si Interface, Phys Rev B, 38 (1988) 6084-6096.

[36] F.J. Himpsel, A. Talebibrahimi, J.A. Yarmoff, G. Hollinger, Microscopic Structure of the Sio2/Si Interface, J Electrochem Soc, 135 (1988) C136-C136.

[37] M.Y. Bashouti, K. Sardashti, J. Ristein, S.H. Christiansen, Early stages of oxide growth in $\mathrm{H}$-terminated silicon nanowires: determination of kinetic behavior and activation energy, Phys Chem Chem Phys, 14 (2012) 11877-11881.

[38] M. Bashouti, K. Sardashti, J. Ristein, S. Christiansen,. Kinetic study of $\mathrm{H}$-terminated silicon nanowires oxidation in very first stages, Nanoscale res. lett, 8 (1), 41 (2013)

[39] T.K. Whidden, P. Thanikasalam, M.J. Rack, D.K. Ferry, Initial Oxidation of Silicon(100) - a Unified Chemical-Model for Thin and Thick Oxide-Growth Rates and Interfacial Structure, J Vac Sci Technol B, 13 (1995) 1618-1625.

[40] D.D.D. Ma, C.S. Lee, F.C.K. Au, S.Y. Tong, S.T. Lee, Smalldiameter silicon nanowire surfaces, Science, 299 (2003) 1874-1877.

[41] D.B. Mawhinney, J.A. Glass, J.T. Yates, FTIR study of the oxidation of porous silicon, J Phys Chem B, 101 (1997) 1202-1206.

[42] R.H. Tian, O. Seitz, M. Li, W.C. Hu, Y.J. Chabal, J.M. Gao, Infrared Characterization of Interfacial Si-O Bond Formation on Silanized Flat SiO2/Si Surfaces, Langmuir, 26 (2010) 4563-4566.

[43] D.K. Schwartz, Mechanisms and kinetics of self-assembled monolayer formation, Annu Rev Phys Chem, 52 (2001) 107137.

[44] R.G. Nuzzo, B.R. Zegarski, L.H. Dubois, FundamentalStudies of the Chemisorption of Organosulfur Compounds on $\mathrm{Au}(111)$ - Implications for Molecular Self-Assembly on Gold Surfaces, J Am Chem Soc, 109 (1987) 733-740.

[45] V.A. Sivakov, R. Scholz, F. Syrowatka, F. Falk, U. Gosele, S.H. Christiansen, Silicon nanowire oxidation: the influence of sidewall structure and gold distribution, Nanotechnology, 20 (2009).

[46] M.Y. Bashouti, Y. Paska, S.R. Puniredd, T. Stelzner, S. Christiansen, H. Haick, Silicon nanowires terminated with methyl functionalities exhibit stronger $\mathrm{Si}-\mathrm{C}$ bonds than equivalent 2D surfaces, Phys Chem Chem Phys, 11 (2009) 3845-3848.

[47] O. Assad, S.R. Puniredd, T. Stelzner, S. Christiansen, H. Haick, Stable Scaffolds for Reacting Si Nanowires with Further Organic Functionalities while Preserving Si-C Passivation of Surface Sites, J Am Chem Soc, 130 (2008) 17670-+

[48] S.R. Puniredd, O. Assad, H. Haick, Highly stable organic monolayers for reacting silicon with further functionalities: 
The effect of the C-C bond nearest the silicon surface, J Am Chem Soc, 130 (2008) 13727-13734.

[49] S.R. Puniredd, O. Assad, T. Stelzner, S. Christiansen, H. Haick, Catalyst-Free Functionalization for Versatile Modification of Nonoxidized Silicon Structures, Langmuir, 27 (2011) 4764-4771

[50] M. Y. Bashouti, M. Pietsch, G. Brönstrup, V. Sivakov, Jürgen Ristein, S. Christiansen, Hybrid polymer / silicon nanowire solar cell with high efficiency through covalent Si-C terminated surface passivation. Prog. Photovolt: Res. Appl., (2013). (Online).

[51] M.C. Putnam, S.W. Boettcher, M.D. Kelzenberg, D.B. TurnerEvans, J.M. Spurgeon, E.L. Warren, R.M. Briggs, N.S. Lewis,
H.A. Atwater, Si microwire-array solar cells, Energ Environ Sci, 3 (2010) 1037-1041.

[52] B.Z. Tian, X.L. Zheng, T.J. Kempa, Y. Fang, N.F. Yu, G.H. Yu, J.L. Huang, C.M. Lieber, Coaxial silicon nanowires as solar cells and nanoelectronic power sources, Nature, 449 (2007) 885-U888.

[53] S. Maldonado, D. Knapp, N.S. Lewis, Near-ideal photodiodes from sintered gold nanoparticle films on methyl-terminated Si(111) surfaces, J Am Chem Soc, 130 (2008) 3300-+.

[54] M. Ambrico, P. F. Ambrico, R, di Mundo, Electrical transport Features of SiNWs Random Network on Si Support After Covalent Attachment of New Organic Functionalities, Nanomater. Nanotechnol, 2, (2012), 1-8. 